\title{
A Case Study on American English Front Vowel Quality and How Native Language Transfer Could Affect Pronunciation
}

\author{
Xiaomu Ren \\ Graduate School of Arts \& Sciences, Department of Linguistics, University of Virginia, \\ Charlottesville, Virginia, United States \\ gdrenxiaomu@sina.com
}

Keywords: Native language transfer, American English, Mandarin, Front vowels, Vowel formants, F1, F2

Abstract: Daily communication shows that some English front vowels are distinguishably produced by American English speakers and Mandarin speakers. Applying acoustic research method, this paper conducts a case study involving three native English speakers and three Mandarin speakers. The comparison is made between these two groups of speakers on the mean of F1 and F2 of front vowels /i:/, /I/, /eI/, / / /, /æ/. Based on the measurement of vowel quality, this research also explores that in what ways or to what degree native language transfer could affect the pronunciation.

\section{Introduction}

\subsection{Research background}

Negative transfer or positive transfer is a behavioral psychology term referring to the interference of the previous knowledge with new learning. The transfer in language addresses the phenomenon that speakers or writers applying the knowledge from one language to another, especially from their native language to a nonnative language. This negative transference of mother language shows the language interference could be the source of error. In second language teaching, negative transfer, which much wider exists within the native language and target language, is more highlighted than positive transfer. Native language transfer, wildly spread, is possibly presented by any nonnative speakers in any linguistic elements.

According to Prator and Robinett (1985), /i:/, /I/, /eI/, / / /, /æ/ are categorized as front vowels in English. Prator and Robinett (1985:13) also pointed out that the recognition of vowel phones is required for mutual intelligibility of both speakers and receivers. Vowels are crucial in language communication.

And it is well-known that most of $\mathrm{L} 2^{1}$ speakers do not have many difficulties in writing, but suffer a lot in listening and speaking. English, as an obligatory subject in China, is learnt by Chinese children from very young age. From my observation, it is still a tedious process for Chinese

\footnotetext{
${ }^{1}$ Second language
} 
speakers to produce some of those English front vowels successfully.

I do not attribute this to the lack of practice or contact with L2 environment. Most adults who learn a foreign language and speak it with a discernible foreign accent even after decades of practice (Tahta-Wood-Loewenthal 1981; Flege 1988a). Exactly, Mandarin speakers are intended to produce English front vowels in a "Chinese way" which sometimes is bantered as "Chinglish". Also, Singapore English are called "Singlish". The serious impact of native language, which is said to be native language negative transfer, accounts for the phenomenon.

\subsection{Literature review}

The history of acoustic experiments can be traced back to 1922. Paget (1976) recorded the first experiment of English vowels. Later on, Fry (1962) explored vowel identification and claimed that F1 and F2 are adequate to distinguish vowel quality.

The second language acoustic experiments have come into the picture since the late 1980's (Fokes \& Bond 1989; Flege 1987a, 1987b, 1987c; Munro 1993). Thereinto, Flege (1987b) manifests that production of $\mathrm{L}^{2}$ categories shifts toward the phonetic norms of similar L2 categories when it is a new L2 phone with no counterpart found in L1 and the speakers have been living in an L2 environment for a long time. Before that, another research carried out by Flege and Hillenbrand (1984) presents that English L1 speakers can better produce French /y/ which does not have a phonemic counterpart in English than French /u/ which exists in both French and English.

The research of Mandarin speakers' English acoustic research is not commonly seen. Mandarin is an intonation language belonging to Sino-Tibetan language family which is very different from European languages. Molholt (1988) claims that Mandarin speakers' English pronunciation is of a relatively high frequency. His research also points out that Mandarin speakers have difficulty in controlling the duration when producing / $\mathrm{I} /$ which could lead to the same duration of /i:/. Besides, he noticed that $/ \varepsilon /$ and $/ æ /$ are also the problem for Mandarin speakers.

Molholt did not further mention any phonemic relation between L1 and L2 or any impact that L1 would generate on L2. Nevertheless, Molholt was one of earliest scholars who carried out the acoustic research on Mandarin speakers' English pronunciation. His research provides second language teaching with important Mandarin speakers' acoustic information by showing the articulatory place, depth and types of those inaccurate pronunciations.

\subsection{Hypotheses}

(1) $/ \mathrm{i}: /, / \varepsilon /$ and /eI/ are produced with least difference by American English speakers and Mandarin speakers.

(2) /I/ produced by Mandarin speakers has lower F1 and higher F2. (I.e., /I/ produced by Mandarin speakers is higher, fronter and get more close to /i:/ )

(3) /æ/ produced by Mandarin speakers has lower F1 and lower F2. (I.e., /æ/ produced by Mandarin speakers is higher, more central and get more close to $/ \varepsilon /$.)

\subsection{Grounding}

The grounding for the hypotheses refers to native language transfer. And the description "new", “identical” and "similar" referring to L2 phones was put forward by Flege (1987).

Based on that, I make another claim that the degree of pronunciation difficulty is affected by the native language transfer. And the effect could be either positive or negative. Firstly, nonnative

\footnotetext{
${ }^{2}$ Primary language/ native language/ first language
} 
speakers have least difficulty in producing a L2 phone which is found identical in L1. And the acquisition of the identical phones in $\mathrm{L} 2$ are benefited from positive native language transfer. Secondly, nonnative speakers are able to produce a L2 phone which have no counterpart found in L1, or differs acoustically from phones found in L1. Flege termed these as "new phones". The new phones in L2 is not affected by native language transfer. Thirdly, nonnative speakers will be affected by the native language dramastically in producing similar phones in L2 which systematically differ from any easily discernible counterpart in L1.

To address this question, the case study is to test the degree of native language transfer by setting Mandarin as L1 and English as L2. Native language transfer exists in all kinds of second language acquisition. To some extent, the case study reflects this universal linguistic phenomenon.

\section{Methods}

Gender and geographic facts are not considered as an issue in this research. So 3 Mandarin speakers (2 males and 1 female) and 3 American English speakers (3 females) are involved. All of them comes from different part of the native country.

The sentence is "I say___now." The sentence list instead of word list is chosen for the speakers in order to make it similar to a daily communication. And the key words are in a / $\mathrm{dVt} / \mathrm{pattern}$ : beat, bait, bet, bit and bat. The word-initial and word-final consonant is controlled to be the same, in order to make sure that the speakers will not be affected by the variation of consonants.

The average F1 and F2 of Mandarin speakers and American English speakers will be measured. The standard derivation shows the stability of F1 and F2 in each group of speakers. Moreover, T-test results are employed to determine the significant difference between each set of data.

\section{Results and Analysis}

Table 1: "I say beat now"

\begin{tabular}{lccc}
\hline Group & Vowel & F1/F2 Mean (Hz) & F1/F2 Std. Dev. \\
\hline $\begin{array}{l}\text { American } \\
\text { English speakers }\end{array}$ & /i:/ & $346 / 2622$ & $67.57 / 281.77$ \\
Mandarin Speakers & /i:/ & $360 / 2322$ & $93.04 / 352.27$ \\
\hline $\begin{array}{l}\text { English speakers'/i:/ } \\
\text { \&Mandarin speakers'/i:/ }\end{array}$ & F1 & F2 \\
\hline T-test & $\mathrm{t}(2)=0.182, \mathrm{p}=0.8725$ & $\mathrm{t}(2)=1.077, \mathrm{p}=0.394$
\end{tabular}

The data supports the hypothesis (1). We can see from the mean of F1 and F2 that the /i:/ produced by Mandarin speakers is slightly lower and more central (higher F1 and lower F2). But the T-test shows there is no significant difference between the /i:/ produced by Mandarin and American English speakers. 
Table 2: "I say bait now"

\begin{tabular}{lccc}
\hline Group & Vowel & F1/F2 Mean (Hz) & F1/F2 Std. Dev. \\
\hline $\begin{array}{l}\text { American } \\
\text { English speakers }\end{array}$ & /eI/ & $491 / 2400$ & $66.55 / 155.76$ \\
Mandarin Speakers & /ei/ & $602 / 2051$ & $44.56 / 416.10$ \\
\hline $\begin{array}{l}\text { English speakers'/ei/ } \\
\text { \&Mandarin speakers'/eI/ }\end{array}$ & $\mathrm{F} 1$ & F2 \\
\hline T-test & $\mathrm{t}(2)=2.704, \mathrm{p}=0.114$ & $\mathrm{t}(2)=1.141, \mathrm{p}=0.372$
\end{tabular}

This group of data shown in Table 2 holds up the hypothesis (1). The T-test shows no significant difference between the /es/ produced by Mandarin and American English speakers, even though we can find in the data that /ei/ is lower and more central (higher F1 and lower F2) when it is pronounced by Mandarin speakers. But the overall situation manifests that Mandarin speakers have no much difficulty in producing /eı/.

Table 3: "I say bet now"

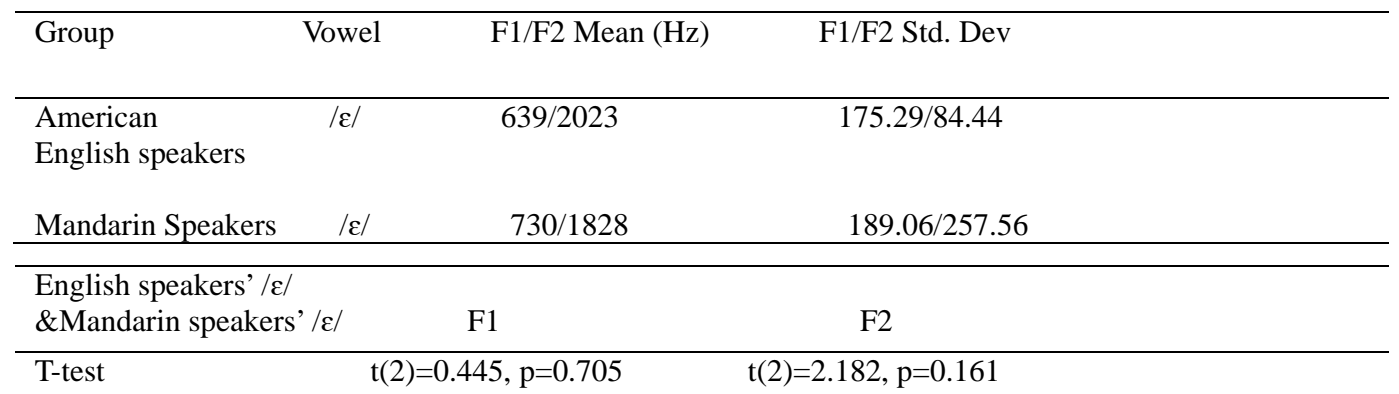

Table 3 displays the resemble situation to the first two. Shown by the mean of F1 and F2, / $/$ / is lower and more central when it is produced by Mandarin speakers. However, the T-test displays no significant difference. Based on the T-test, the results show that Mandarin speakers have few difficulty in producing English front vowel / $\varepsilon /$ as well.

Table 4: "I say bit now"

\begin{tabular}{lccc}
\hline Group & Vowel & F1/F2 Mean $(\mathrm{Hz})$ & F1/F2 Std. Dev \\
& & & \\
\hline American & /I/ & $575 / 2136$ & $39.80 / 99.34$ \\
English speakers & & & \\
Mandarin Speakers & /I/ & $384 / 2276$ & $71.08 / 429.83$ \\
\hline $\begin{array}{l}\text { English speakers'/I/ } \\
\text { \&Mandarin speakers'/I/ }\end{array}$ & $\mathrm{F} 1$ & $\mathrm{~F} 2$ \\
\hline T-test & $\mathrm{t}(2)=4.70, \mathrm{p}<0.05$ & $\mathrm{t}(2)=0.624, \mathrm{p}=0.596$
\end{tabular}

The data given in Table 4 supports the hypothesis (2). The T-test of F1 indicates the significant difference of the pronunciation of /I/ by American English speakers and Mandarin speakers. /I/ is obviously higher (lower F1) according to Mandarin speakers' pronunciation. And it is slightly fronter (higher F2) when pronounced by Mandarin speakers. So /I/ produced by Mandarin speakers 
is almost like /i:/. The difference of F2 is less obvious because /I/ and /i:/ are both front vowels.

Table 5: "I say bat now."

\begin{tabular}{lccc}
\hline Group & Vowel & F1/F2 Mean (Hz) & F1/F2 Std. Dev \\
& & & \\
\hline $\begin{array}{l}\text { American } \\
\text { English speakers }\end{array}$ & $/ æ /$ & $882 / 1922$ & $181.502 / 174.992$ \\
Mandarin Speakers & $/ æ /$ & $664 / 1889$ & $174.760 / 132.106$ \\
\hline $\begin{array}{l}\text { English speakers'/æ/ } \\
\text { \&Mandarin speakers'/æ/ }\end{array}$ & $\mathrm{F} 1$ & $\mathrm{~F} 2$ \\
\hline T-test & $\mathrm{t}(2)=1.085, \mathrm{p}=0.391$ & $\mathrm{t}(2)=1.191, \mathrm{p}=0.356$
\end{tabular}

Presented by Table 5, /æ/ needs more discussion. T-test demonstrates no significant difference between the pronunciation of Mandarin speakers and American English speakers. However, seen from the mean of F1 and F2, it clearly shows the articulatory place of /æ/ is upper and central when pronounced by Mandarin speakers.

In order to clearly examining the variation, the comparison is made between the English speakers' $/ æ /$ and $/ \varepsilon /$, and also between the Mandarin speakers' $/ æ /$ and $/ \varepsilon /$. The result shows that the T-test of $/ æ /$ and $/ \varepsilon /$ produced by American English speakers with noticeable difference. Compared with that, the T-test of Mandarin speakers'ææ/ and / $/ \varepsilon /$ shows $/ æ /$ and $/ \varepsilon /$ produced by Mandarin speakers with no difference. And looking back at the mean F1 and F2 of Mandarin speakers' $/ \varepsilon /$, we can find that the statistics is nearly identical to the mean F1 and F2 of Mandarin speakers’ææ/.

Table 6: T-test of

\begin{tabular}{|c|c|c|}
\hline $\begin{array}{l}\text { English speakers’ææ/ } \\
\text { \&English speakers'/ع/ }\end{array}$ & F1 & F2 \\
\hline T-test & $\mathrm{t}(2)=6.65, \mathrm{p}<0.05$ & $\mathrm{t}(2)=0.447, \mathrm{p}=0.698$ \\
\hline $\begin{array}{l}\text { Mandarin speakers'/æ/ } \\
\& \text { Mandarin speakers'/ع/ }\end{array}$ & F1 & F2 \\
\hline
\end{tabular}

According to the statistics, the hypothesis (3) is supported. /æ/ produced by Mandarin speakers is higher, more central and get more close to $/ \varepsilon /$.

Based on the data above, the front vowel chart is shown below. This vowel chart demonstrates the front vowels produced by both Mandarin speakers and American speakers. F2 is on the X-axis, while F1 is on Y-axis. The vowel chart shows the vowel quality of the English front vowels when produced by Mandarin speakers and American English speakers. And it shows that the vowels pronounced by Mandarin speakers are all relatively more central and in higher position. 
Table 7: Front Vowels Chart

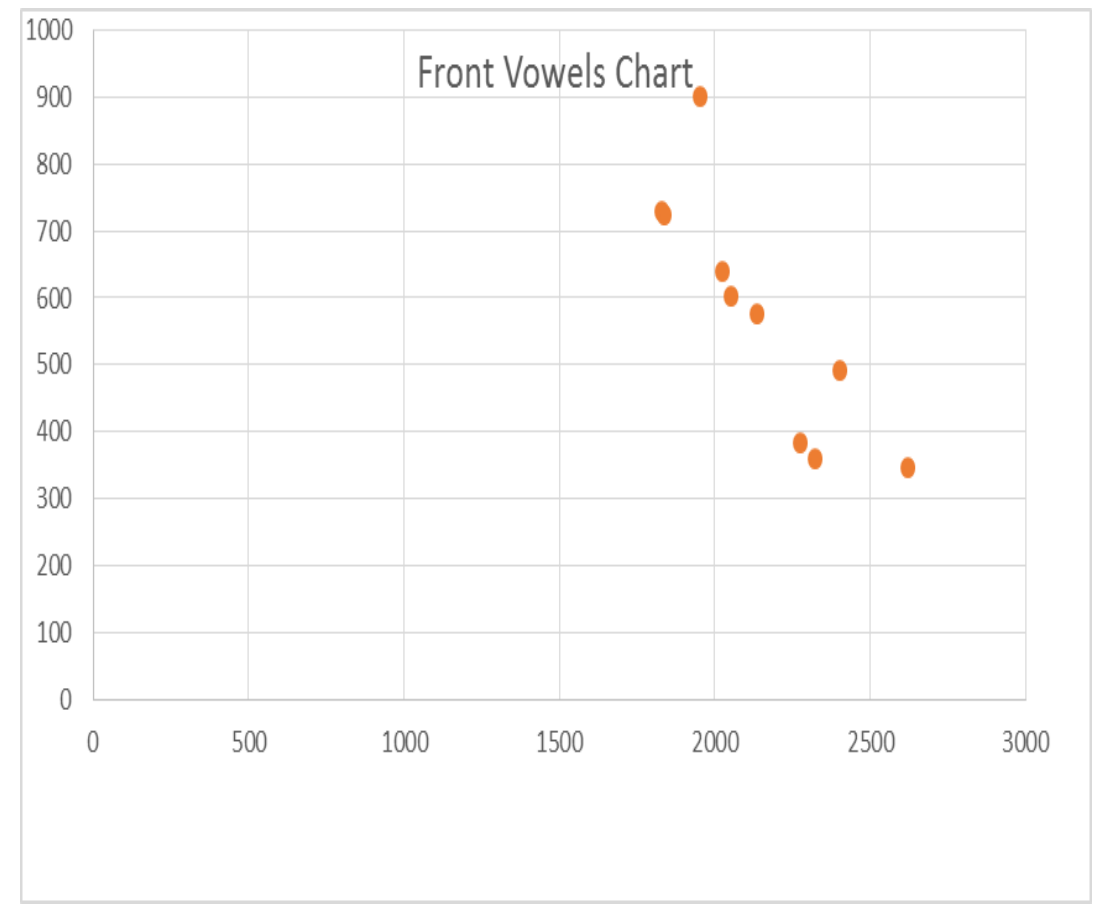

\section{Discussion}

The results support the original research questions and prove the grounding. It appears that the front vowels /i:/ and /ei/ are the easiest for Mandarin speakers to produce. Because the exactly identical counterparts are found in Mandarin. And /i:/ and /ei/ are the wildly used vowels in Mandarin. The statistics of $/ \varepsilon /$ demonstrates that Mandarin speakers have no difficulty in pronouncing it. It is a new L2 phone for Mandarin speakers which has no counterpart or acoustically similar phone in L1. And this prevents the L1 speakers being negatively influenced by their native language.

Nevertheless, /I/ is a similar L2 phone which causes greatest difficulty for Mandarin speakers. And / $\mathrm{I}$ / is resemble to /i:/ which exists in Mandarin as well. So Mandarin speakers are inclined to pronounce /I/ as /i:/ which is higher and fronter with a longer duration. /æ/ is also a similar L2 phone. In Mandarin, the resemble sound is /æy/.

And this is what the vowel chart in former section has shown to us. Mandarin speakers are inclined to pronounce more central and higher phones. Because nearly all of the Mandarin phones are quite central and higher, which generates the negative transfer on some of the English front vowel pronunciation. But it is a positive transfer on the English vowel like /i:/ and /eI/.

The possible source of error is the comparatively small sample of speakers (6 speakers) due to the limitation of time and venue. English proficiency of the three speakers is not convincing to fully represent the overall level of Mandarin speakers.

Mandarin and English is chosen as L1 and L2 to conduct the case study. If more comparison is undertaken between different kinds of L1 and L2 and larger sample could be applied, the more accurate results can be proffered.

\section{References}

[1] Flege, J. E. 1987a. A critical period for learning to pronounce foreign languages [J]. Applied Linguistics 8:162-177

[2] Flege, J. E. 1987b. The production of "new" and "similar" phones in a foreign language: Evidence for the effect of 
equivalence classification [J]. Journal of Phonetics 15:47-65.

[3] Flege, J. E. 1987c. Effects equivalence classification on the production of foreign language speech sounds [A]. In A. James \& J. Leather (eds.), Sound Patterns in Second Language Acquisition [C]. Dordrecht: Foris Publications.

[4] Flege, J. E. \& J. Hillenbrand. 1984. Limits of phonetic accuracy in foreign language production [J]. Journal of the Acoustical Society of America 76 (3): 708-721.

[5] Flege, J. E. (1988). The production and perception of foreign language speech sounds. In H. Winitz (Ed.), Human communication and its disorders: a review pp. 224-401

[6] Fokes, J. \& Z. S. Bond. 1989. The vowels of stressed and unstressed syllables in nonnative English [J]. Language Learning 39 (3):341-371.

[7] Fry, D. B. et al. 1962. The identification and discrimination of synthetic vowels [J]. Language and Speech 5:171-189.

[8] Molholt, G. 1988. Computer-assisted instruction in pronunciation for Chinese speakers of American English [J]. TESOL Quarterly 22 (1): 91-111.

[9] Munro, M. J. 1993. Productions of English vowels by native speakers of Arabic: Acoustic measurements and accentedness ratings [J]. Language and Speech 36 (1): 39-66.

[10] Paget, R. S. 1976. Vowel resonances [A]. In D. B. Fry (ed.), Acoustic Phonetics [C]. Cambridge: Cambridge University Press.

[11] Prator, Jr. C. H. \& B. W. Robinett. 1985. Manual of American English Pronunciation [M]. New York: Holt, Rinehart Winston.

[12] Tahta, S., Wood, M. and Loewenthal, K. (1981). Foreign accents: Factors relating to transfer of accent from the first language to a second language. Language and Speech, 24, 265-272. 